\title{
CIP2A depletion potentiates the chemosensitivity of cisplatin by inducing increased apoptosis in bladder cancer cells
}

\author{
FENGBIN GAO $^{1 *}$, XIAOJING WANG ${ }^{1 *}$, SHANWEN CHEN $^{2 *}$, \\ TIANYUAN XU ${ }^{1}$, XIANJIN WANG ${ }^{2}$, YIFAN SHEN ${ }^{2}$, \\ FAN DONG $^{2}$, SHAN ZHONG $^{2}$ and ZHOUJUN SHEN ${ }^{1,2}$ \\ ${ }^{1}$ Department of Urology, Ruijin Hospital Affiliated to The School of Medicine, \\ Shanghai Jiaotong University, Shanghai 200025; ${ }^{2}$ Department of Urology, \\ Huashan Hospital Affiliated to Fudan University, Shanghai 200040, P.R. China
}

Received April 18, 2018; Accepted July 17, 2018

DOI: $10.3892 /$ or.2018.6641

\begin{abstract}
Poor response and chemotherapy resistance to cisplatin (DDP)-based therapy frequently lead to treatment failure in advanced bladder cancer; however the underlying mechanism is extremely complex and unclear. Furthermore, cancerous inhibitor of protein phosphatase 2A (CIP2A), a recently identified human oncoprotein, has been shown to play important regulatory roles in cancer cell survival. The present study aimed to investigate the correlation of CIP2A with sensitivity to DDP in bladder cancer cells. In the present study, knockdown of CIP2A was performed using short hairpin-RNA. $\mathrm{IC}_{50}$ determination was used to estimate the chemosensitivity of cells to DDP. Apoptosis and DNA damage indicators were tested in vitro and in vivo to clarify the role of CIP2A in enhancing DDP sensitivity. We observed that CIP2A knockdown enhanced DDP sensitivity. CIP2A depletion accelerated the process of DNA damage caused by DDP treatment. Furthermore, DDP triggered inhibition of CIP2A
\end{abstract}

Correspondence to: Professor Zhoujun Shen, Department of Urology, Ruijin Hospital Affiliated to The School of Medicine, Shanghai Jiaotong University, 197 Ruijin 2nd Road, Shanghai 200025, P.R. China

E-mail: shenzj68@sina.cn

Professor Shan Zhong, Department of Urology, Huashan Hospital Affiliated to Fudan University, 12 Middle Urumqi Road, Shanghai 200040, P.R. China

E-mail: zhongshan579@163.com

*Contributed equally

Abbreviations: DDP, cisplatin; CIP2A, cancerous inhibitor of protein phosphatase $2 \mathrm{~A}$; MIBC, muscle-invasive bladder cancer

Key words: CIP2A, cisplatin, apoptosis, DNA damage, chemosensitivity, bladder cancer by preventing AKT Ser473 phosphorylation. In vivo, CIP2A suppression increased the cytotoxicity of DDP, which resulted in a decrease in the subcutaneous tumor growth in a xenograft mouse model. Our findings revealed that the mechanism underlying the involvement of CIP2A in DDP sensitivity enhancement is that CIP2A mediates DDP-induced cell apoptosis and DNA damage. CIP2A is a potential target to improve the response to DDP-based therapy in bladder cancer patients.

\section{Introduction}

Based on the invasion of lamina propria, urothelial bladder cancer is clinically divided into muscle-invasive bladder cancer (MIBC) and non-muscle-invasive bladder cancer. Particularly for MIBC, the characteristics including a high occurrence rate of distant metastases and a low 5-year survival rate demand a high level of efficacy of the therapeutic regimen (1). Cisplatin (DDP), as the backbone of combination chemotherapies, is the first-line drug for patients with advanced bladder cancer (2). Several large, randomized trials and meta-analyses provide convincing evidence to support the clinical feasibility and survival benefit of neoadjuvant DDP-based chemotherapy compared with surgery alone in patients with MIBC (3-5). Although bladder cancer is relatively chemosensitive for standard first-line therapy (such as gemcitabine plus DDP or methotrexate, vinblastine, doxorubicin and DDP), $30 \%$ of MIBC patients still present with a resistant response to the aforementioned DDP-based therapeutic regimens and have a very poor prognosis with only a 14 month overall survival period $(6,7)$. There is no consensus in how to manage MIBC patients who experience the failure of DDP-based first-line therapy. In addition, DDP-based regimens are frequently associated with adverse effects, including renal toxicity and gastrointestinal disorders, which cause obstacles for therapeutic efficacy, drug continuation and tolerability (8).

Apoptosis is a controlled type of cell death, which is characterized by chromatin condensation and membrane 
budding (9). DDP primarily induces cancer cell apoptosis, and failure of the apoptotic pathway may be the major factor in DDP resistance (10). With respect to the molecular mechanisms, cross-linked compounds of DNA and DDP contribute to cytotoxicity by interfering with DNA replication and inducing DNA damage, which in turn triggers the process of apoptosis (11). Defects in the repair of DNA damage induced by regimens represent an essential mechanism of cytotoxic chemotherapy sensitivity (12). Several studies support the role of various DNA-repair genes, such as breast cancer susceptibility gene 1, excision repair cross-complementing group 1, ataxia-telangiectasia mutated kinase, and retinoblastoma gene 1 as biomarkers of DDP-based chemotherapy sensitivity $(13,14)$.

Cancerous inhibitor of protein phosphatase 2A (CIP2A), an oncoprotein with many roles in biological functions, is overexpressed at a high frquency in a number of tumors, and performs its oncogenic functions by participating in multiple pathways, including the phosphoinositide-3-kinase $(\mathrm{PI} 3 \mathrm{~K}) / \mathrm{R}$ AC- $\alpha$ serine/threonine-protein kinase (AKT), RAS/ERK and the Wnt/ $\beta$-catenin pathway (15). Our previous study revealed the close relationship between the aberrant expression of CIP2A and uncontrolled cell proliferation in bladder cancer (16). CIP2A depletion contributes to cell apoptosis in several cancer types (17). Functional studies also confirmed the potential role of CIP2A in sensitizing cancer cells to many chemotherapeutic agents (18). Exploring novel approaches to bladder cancer treatment to increase sensitivity to DDP is a critical issue; however, the advent of targeted therapy is promising.

In this context, the present study was designed to explore the significance and potential of CIP2A in enhancing the chemosensitivity of DDP in bladder cancer. In the present study, we demonstrated that inhibition of CIP2A exacerbated DDP-induced bladder cancer cell apoptosis by the accumulation of DNA damage. Furthermore, we further explored the role of the AKT pathway in DDP-triggered CIP2A inhibition.

\section{Materials and methods}

Cell culture and chemicals. Human urothelial bladder cancer cell lines T24 and J82 were obtained from the Type Culture Collection of the Chinese Academy of Sciences, (Shanghai, China) and were cultured in Dulbecco's modified Eagle's medium (HyClone Laboratories; GE Healthcare Life Sciences, Logan, UT, USA) and supplemented with $10 \%$ fetal bovine serum (FBS; Gibco; Thermo Fisher Scientific, Inc., Waltham, MA, USA). Cells were cultured at $37^{\circ} \mathrm{C}$ with $5 \% \mathrm{CO}_{2}$. DDP (Sigma-Aldrich, Merck KGaA, Darmstadt, Germany) was dissolved in phosphate-buffered saline (PBS) for cell incubation. The PI3K inhibitor LY294002 was purchased from Selleck Chemicals (Houston, TX, USA).

$R N A$ extraction and reverse transcription-quantitative polymerase chain reaction $(R T-q P C R)$. Total RNA extraction and reverse-transcription reactions were performed using an RNA Extraction kit (Takara Bio, Inc., Otsu, Japan) and PrimeScript ${ }^{\mathrm{TM}}$ RT Master Mix (Takara Bio, Inc.), respectively. The following primers were used for amplification: CIP2A, forward primer, 5'-CACAAAT-CACCTCGAC CCCT-3' and reverse primer, 5'-CAAAAGCTGAGTGGC GTTCG-3'. $\beta$-actin was used as an internal control: Forward primer 5'-GTGGGGCGCCCCCAGGCACCA-3' and reverse primer, 5'-CTCCTTAATGTCACGCACGAT-3'. RT-qPCR was performed using Power SYBR Green PCR Master Mix (Thermo Fisher Scientific, Inc.). Analysis of the relative gene expression data was performed using quantitative PCR and the $2^{-\Delta \Delta \mathrm{Cq}}$ method (19).

Western blot analysis. Following cell lysis by ice-cold radioimmunoprecipitation assay buffer, protein concentrations were determined. Equal quantities $(30 \mu \mathrm{g})$ of protein were separated using 10\% SDS-polyacrylamide gels, transferred to a polyvinylidene difluoride (PVDF) membrane and blocked with $5 \%$ bovine serum albumin (BSA). PVDF membranes were incubated overnight at $4^{\circ} \mathrm{C}$ with the following antibodies: CIP2A (dilution 1:500; cat. no. sc-80662; Santa Cruz Biotechnology, Inc., Dallas, CA, USA), AKT (dilution 1:1,000; cat. no. 9272S; Cell Signaling Technology, Inc., Danvers, MA, USA), phosphorylated (p)-AKT (dilution 1:1,000; cat. no. 4060S; Cell Signaling Technology), B cell lymphoma-2 (Bcl-2; dilution 1:1,000; cat. no. sc-492; Santa Cruz Biotechnology, Inc.), caspase-3 (dilution 1:1,000; cat. no. 9662S; Cell Signaling Technology), poly(ADP-Ribose) polymerase (PARP; dilution 1:1,000; cat. no. 5625T; Cell Signaling Technology), $\gamma$-H2AX (dilution 1:1,000; cat. no. ab2893; Abcam, Cambridge, UK) and $\beta$-actin (dilution 1:1,000; cat. no. sc-47778; Santa Cruz Biotechnology, Inc.). After being washed, the membranes were then incubated with horseradish peroxidase-conjugated secondary antibodies (anti-mouse IgG, dilution 1:1,000; cat. no. 7076S; Cell Signaling Technology; anti-rabbit IgG, dilution 1:1,000; cat. no. 7074S; Cell Signaling Technology) followed by enhanced chemiluminescence detection.

Construction of stably transfected cells. The CIP2A short hairpin RNA (sh-CIP2A) plasmid, ligated in the pGV101 vector, was purchased from GeneChem Technologies Co., Ltd. (Shanghai, China). The oligonucleotide sequence for shRNA was as follows: 5'-GATCCCCCACAGTTTAAGTGGTGGAAACTCGAGTTT CCACCACTTAAAC TGTGGTTTTTGGAT-3'. sh-CIP2A was transfected using Lipofectamine 2000 (Invitrogen; Thermo Fisher Scientific, Inc.) according to the manufacturer's protocol. In order to obtain stable cell lines, transfected cells were selected with $500 \mu \mathrm{g} / \mathrm{ml}$ neomycin for nearly 2 weeks.

\section{3-(4,5-dimethylthiazol-2-yl)-2,5-diphenyltetrazolium bromide} (MTT) assay. Cells were seeded on a 96-well plate and incubated with different concentrations of DDP $(0,5,10,20$ and $40 \mu \mathrm{g} / \mathrm{ml}$ ). At $24 \mathrm{~h}$ after incubation, cell viability was determined by MTT assay (Invitrogen; Thermo Fisher Scientific, Inc.) using a microplate reader (Multiscan ${ }^{\mathrm{TM}} \mathrm{GO}$; Thermo Fisher Scientific, Inc.). Absorbance was determined at a wavelength of $490 \mathrm{~nm}$. All experiments were performed in triplicate and three wells were used for each treatment. The drug concentration resulting in $50 \%$ inhibition rate $\left(\mathrm{IC}_{50}\right)$ was calculated with GraphPad 6.0 software (GraphPad Software, Inc., La Jolla, CA, USA). 
Colony forming assay. The effect of DDP on the ability of bladder cancer cells to form colonies was assessed using a 6-well plate (200 cells/well). One week after the initial incubation of cells, colonies were incubated with DDP (0 and $5 \mu \mathrm{g} / \mathrm{ml}$ ) for 1 week. The colonies were stained with $0.1 \%$ crystal violet.

Annexin V-PI apoptosis assays. After DDP treatment, the harvested cells were resuspended in Annexin V-binding buffer. Then the cells were stained with FITC-conjugated Annexin V and PI according to the manufacturer's protocol (Invitrogen; Thermo Fisher Scientific, Inc.). After incubation for $30 \mathrm{~min}$ at room temperature in the dark, evaluation of the level of apoptosis was analyzed with a flow cytometer (BD Biosciences, Franklin Lakes, NJ, USA).

Immunofluorescence staining. Cells grown on coverslips in 24-well plates were fixed with $4 \%$ paraformaldehyde and blocked with $5 \%$ bovine serum albumin (BSA). Subsequently, the cells were incubated with antibodies against $\gamma-\mathrm{H} 2 \mathrm{AX}$ (dilution 1:200; cat. no. ab2893; Abcam;) overnight at $4^{\circ} \mathrm{C}$. The secondary antibody (dilution 1:1,000; cat. no. A-21441; Invitrogen; Thermo Fisher Scientific, Inc.) was incubated with the cells at $37^{\circ} \mathrm{C}$ for $1 \mathrm{~h}$, followed by staining with 4',6-diamidino-2-phenylindole (DAPI) to visualize the nuclei. Images were captured using a confocal laser-scanning microscope (Leica SP8; Leica Microsystems GmbH, Wetzlar, Germany).

Comet assay. Slides were pre-coated with $1 \%$ normal melting point agarose. The mixture of $10^{4}$ cells and $70 \mu \mathrm{l}$ $1 \%$ low melting point agarose was rapidly spread onto the pre-coated slides. Subsequently, the slides were immersed in cold lysis buffer for at least $1 \mathrm{~h}$ and alkaline electrophoresis solution for $20 \mathrm{~min}$, successively. Following electrophoresis at $25 \mathrm{~V}$ and $300 \mathrm{~mA}$ for $30 \mathrm{~min}$, the slides were neutralized with Tris- $\mathrm{HCl}(\mathrm{pH} 7.5)$ and dyed with ethidium bromide for $20 \mathrm{~min}$. The individual cells were viewed using an Olympus BX51 UV fluorescence microscope (Olympus Corp., Tokyo, Japan).

Immunohistochemical (IHC) and TUNEL analysis. The slides with paraffin-embedded tissues were deparaffinized in xylene and rehydrated through graded alcohols. Subsequently, $3 \%$ hydrogen peroxide was used to block the endogenous peroxidase activity. The slides were incubated with primary antibodies against CIP2A (dilution 1:50; cat. no. sc-80662; Santa Cruz Biotechnology, Inc.), $\gamma$-H2AX (dilution 1:100; cat. no. ab2893; Abcam) and p-AKT (dilution 1:200; cat. no. 4060S; Cell Signaling Technology). After washing 3 times, diaminobenzidine was used for signal development, and the slides were counterstained with $20 \%$ hematoxylin. Terminal deoxynucleotidyl transferase mediated dUTP nick end labeling (TUNEL) assay was performed using DeadEnd ${ }^{\mathrm{TM}}$ Colorimetric TUNEL system (Promega Corp., Madison, WI, USA), according to the manufacturer's instructions.

Subcutaneous xenograft models. Animal experiments were performed according to the protocol approved by the
Institutional Animal Care and Use Committee of Ruijin Hospital Affiliated to the School of Medicine, Shanghai Jiaotong University. The housing condition for mice is grade SPF (specific-pathogen-free). The temperature is $26-28^{\circ} \mathrm{C}$, and the light/dark cycle is 10/14-h cycle. Sterilized food and water by steam under high pressure were provided to the mice. Twenty 4-week-old female BALB/c nude mice (SLAC Laboratory Animal Co., Ltd., Shanghai, China) were randomly divided into 4 equal groups $(n=5)$. sh-CIP2A and sh-Control T24 cells were harvested to prepare cell suspensions containing $6 \times 10^{6}$ cells $/ \mathrm{ml}$ which were injected into the axillary subcutaneous tissues at $100 \mu \mathrm{l} /$ mouse, respectively. On day 21 when the maximum diameter of the tumors reached $5 \mathrm{~mm}$, intraperitoneal injections of DDP $(2 \mathrm{mg} / \mathrm{kg}$, twice weekly) or an equal volume of $0.9 \%$ normal saline were administered for 3 weeks. To build the tumor growth curve, the tumor volume was determined using calipers every 7 days and calculated with the following formula: Tumor volume $\left(\mathrm{mm}^{3}\right)=\left(\right.$ Length $\left.\mathrm{x} \mathrm{Width}^{2}\right) / 2$. On day 42 , the mice were euthanized via dislocation of cervical vertebra, and meanwhile, the xenograft tumor tissues were removed, weighed and subjected to further IHC staining analysis. The inhibitory rate of DDP was calculated with the formula (1-tumor volume of DDP-treated group/tumor volume of non-DDP-treated group) $\mathrm{x} 100 \%$.

Statistical analysis. Data are expressed as the mean \pm standard deviation (SD), and bars in the graph represent standard deviation. Statistical analyses were conducted using SPSS 22.0 software (IBM, Corp., Armonk, NY, USA). A two-tailed Student's t-test was conducted to analyze statistical differences between groups. P-values of $<0.05$ were considered to indicate statistically significant differences.

\section{Results}

CIP2A depletion increases drug sensitivity to DDP in bladder cancer cells. CIP2A-stable knockdown T24 and J82 cells were successfully established to elucidate the role of CIP2A in chemoresistance to DDP. CIP2A expression was markedly decreased at both the mRNA and protein levels (Fig. 1A and B). Knockdown of CIP2A led to a significant decrease in the $\mathrm{IC}_{50}$ of DDP compared with sh-Control cells (Fig. 1C and D). According to the results of the colony formation experiment following DDP treatment, we observed that inhibition of CIP2A expression significantly decreased the number of colonies formed (Fig. 1E). These results revealed a causal link between CIP2A depletion and the increased chemosensitivity to DDP.

Knockdown of CIP2A induces increased apoptosis in bladder cancer cells upon DDP treatment. Given that apoptosis is one of the major mechanisms responsible for the impairment of proliferation induced by DDP (8), we subsequently investigated the role of CIP2A in DDP-induced apoptosis. Flow cytometry results revealed that upon DDP treatment, the apoptotic rates of sh-CIP2A cells were markedly higher compared with the sh-Control cells (Fig. 2A). Consistently, following DDP treatment, decreased $\mathrm{Bcl} 2$ and increased cleaved caspase- 3 and cleaved PARP were detected in sh-CIP2A T24 and J82 cells 
A

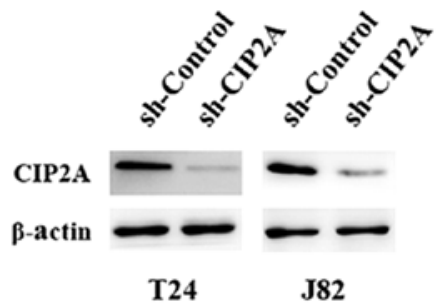

$\mathrm{C}$

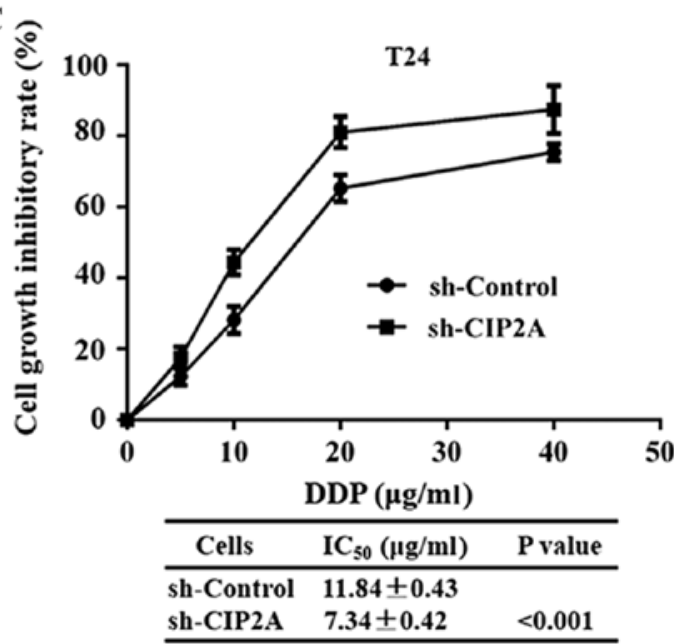

$\mathbf{E}$

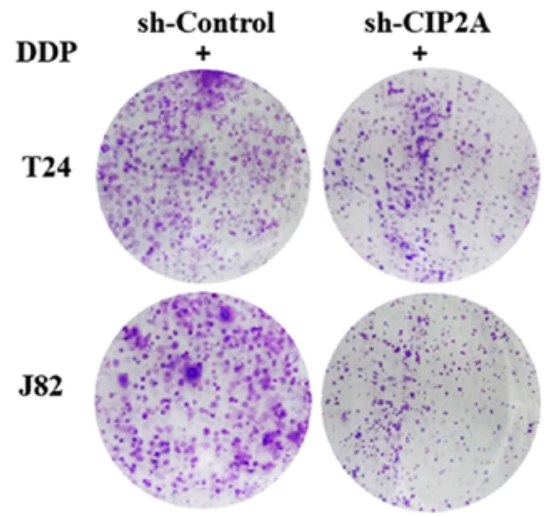

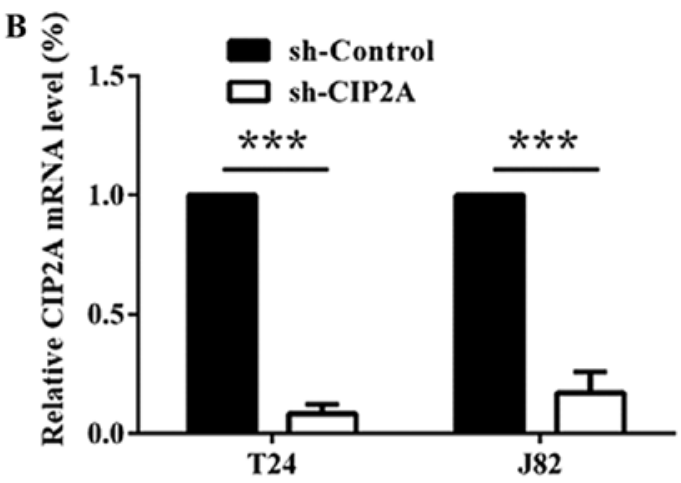

D
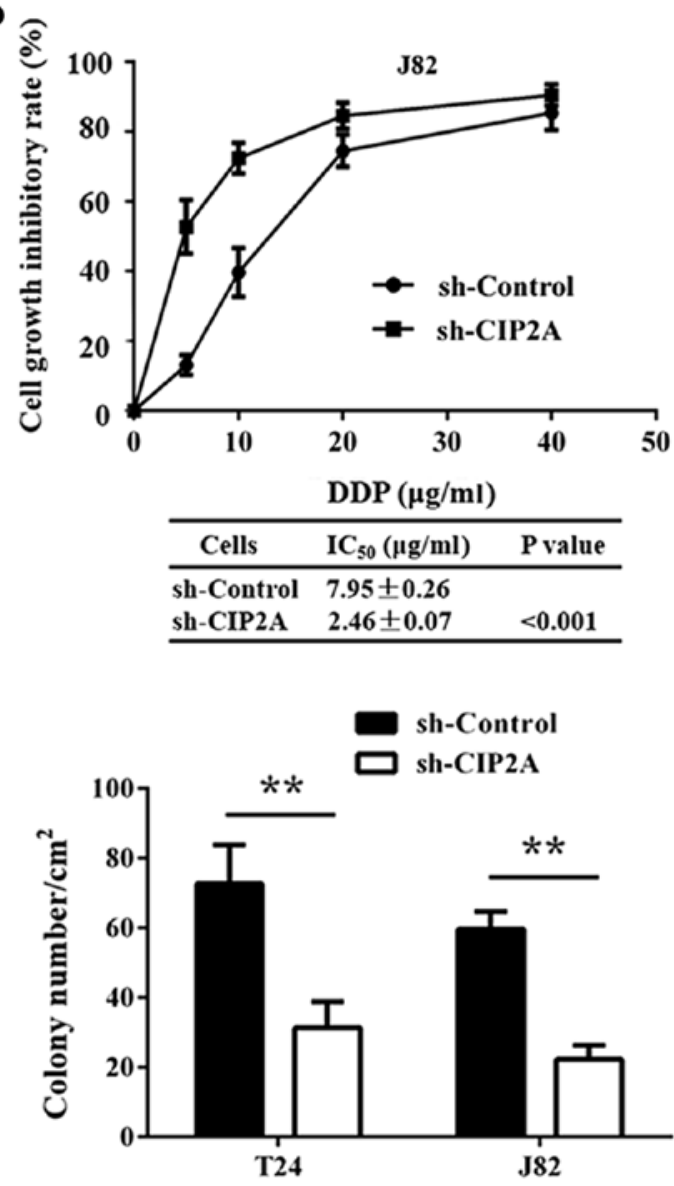

Figure 1. CIP2A depletion increases drug sensitivity to DDP in bladder cancer cells. (A) CIP2A protein and (B) mRNA levels were examined in sh-Control and sh-CIP2A T24 and J82 cells. (C and D) $\mathrm{IC}_{50}$ of DDP was determined by MTT assay upon DDP treatment for $24 \mathrm{~h}$ in sh-Control and sh-CIP2A transfected T24 (C) and J82 (D) cells. (E) The response to DDP was tested by colony formation assay. Cell lines were treated continuously with 0 or $5 \mu \mathrm{g} / \mathrm{ml}$ of DDP for 14 days. Every experiment was conducted at least 3 times. ${ }^{* *} \mathrm{P}<0.01$ and ${ }^{* * * *} \mathrm{P}<0.001$. DDP, cisplatin; sh, short hairpin; CIP2A, cancerous inhibitor of protein phosphatase $2 \mathrm{~A}$.

(Fig. 2B). Therefore, our results indicated that knockdown of CIP2A promoted DDP-induced apoptosis in bladder cancer cells in vitro.

Knockdown of CIP2A in bladder cancer cells enhances DDP-induced DNA damage. DDP can lead to the intracellular accumulation of DNA double-strand breaks (DSBs) and $\gamma$-H2AX protein, which are responsible for cell apoptosis (20). Comet assays confirmed that upon treatment with DDP, both tail DNA content and DNA migration distance of cells with CIP2A downregulation increased significantly compared with the control group (Fig. 3A). In addition, the immunofluorescence images intuitively illustrated that low expression of CIP2A accelerated DDP-induced foci formation of $\gamma-\mathrm{H} 2 \mathrm{AX}$ in T24 and J82 cells (Fig. 3B). Consistently, DDP markedly enhanced the accumulation of $\gamma$-H2AX at the protein level in sh-CIP2A cells (Fig. 3C), indicating that CIP2A depletion may greatly increase the genotoxic effect of DDP in aggravating DNA damage in bladder cancer cells.

DDP attenuates CIP2A expression via the AKT pathway in bladder cancer cells. Based on the aforementioned results, we inferred that CIP2A may serve as a molecular target of 
A
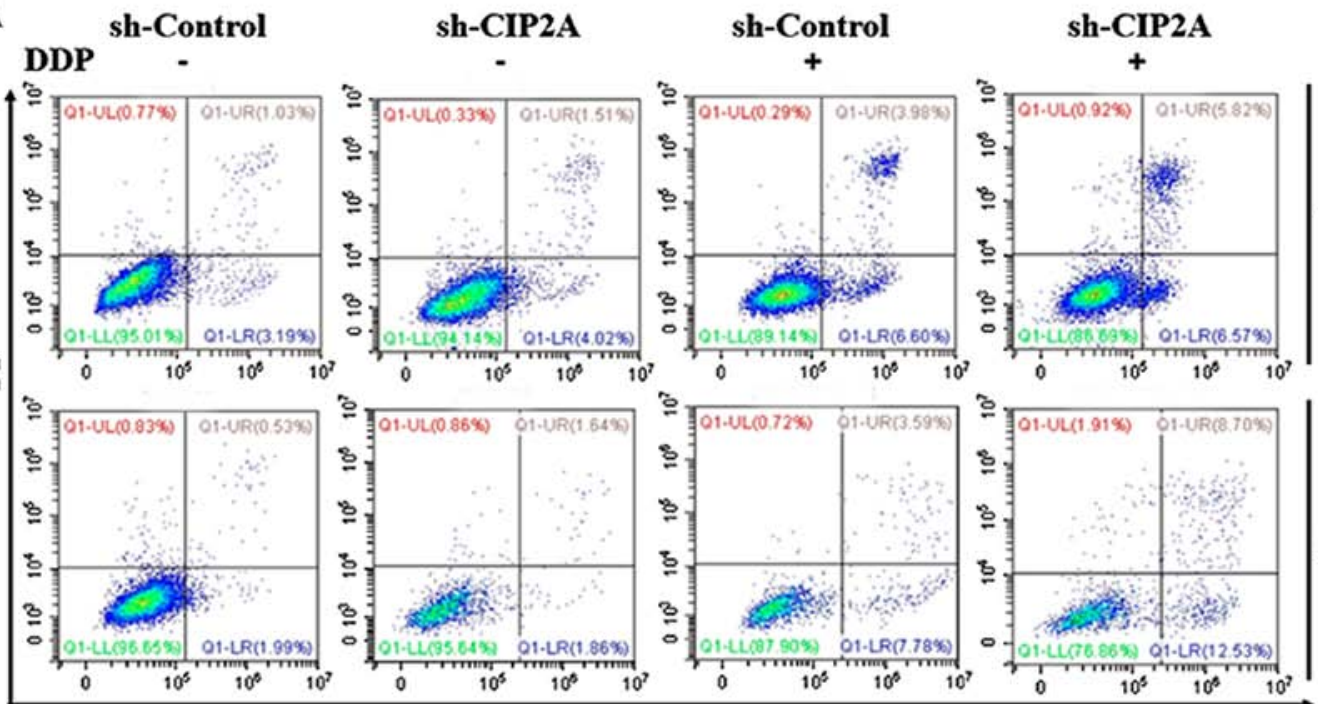

T24

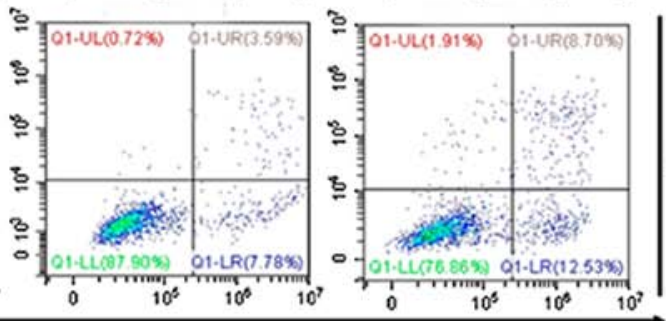

J82

Annexin V-FITC

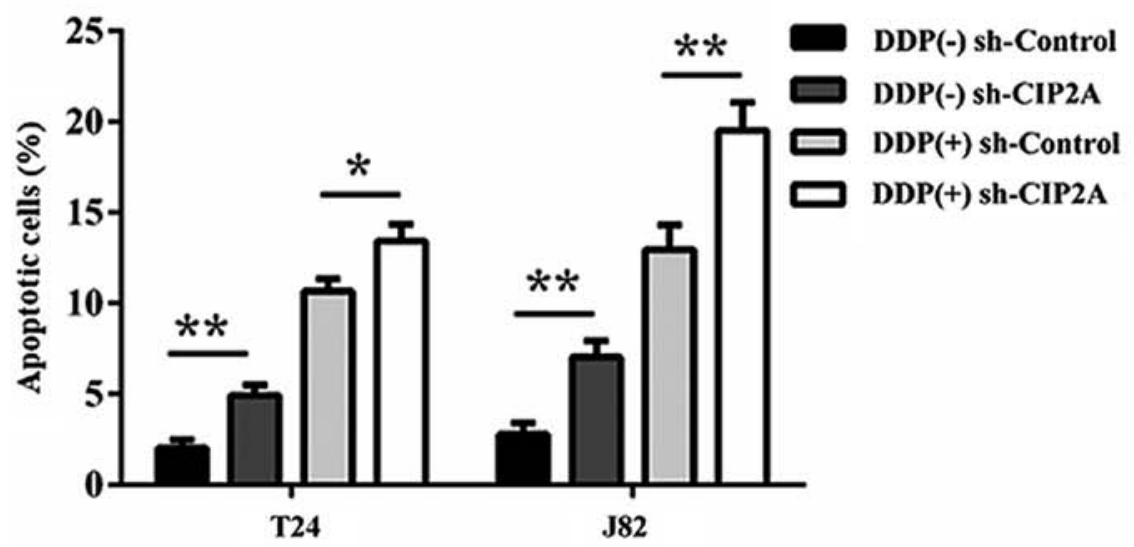

B

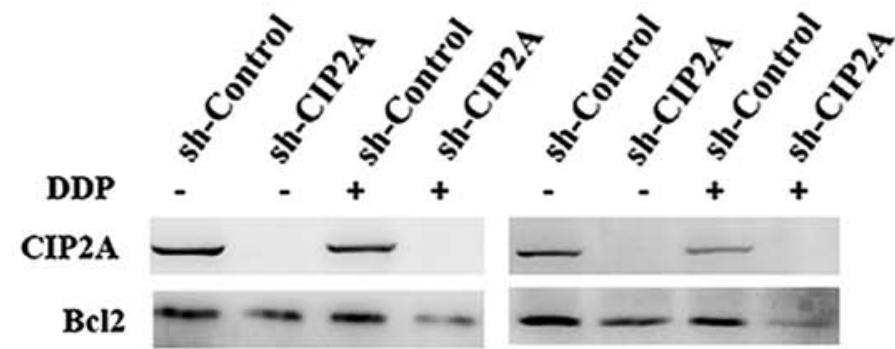

Cleaved caspase-3

Cleaved PARP

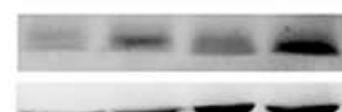

$\beta$-actin

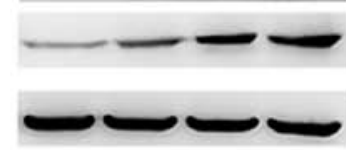

T24

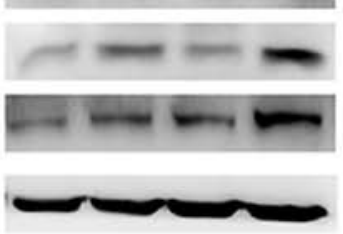

J82

Figure 2. Knockdown of CIP2A induces increased apoptosis in bladder cancer cells upon DDP treatment. (A) Apoptosis of sh-Control and sh-CIP2A bladder cancer cells was demonstrated by flow cytometry with $20 \mu \mathrm{g} / \mathrm{ml}$ of DDP treatment for $24 \mathrm{~h}$. (B) The expression of CIP2A, Bcl2, cleaved caspase-3, and cleaved PARP was detected by western blotting with $20 \mu \mathrm{g} / \mathrm{ml}$ of DDP treatment for $24 \mathrm{~h}$. Every experiment was conducted at least 3 times. ${ }^{*} \mathrm{P}<0.05$, ${ }^{* *} \mathrm{P}<0.01$. DDP, cisplatin; sh, short hairpin; CIP2A, cancerous inhibitor of protein phosphatase 2A.

DDP and play a crucial role in apoptosis, once DDP enters the cells. Following cell exposure for $48 \mathrm{~h}$ to the indicated DDP concentrations, CIP2A was negatively modulated at both the mRNA and protein levels in a dose-dependent manner (Fig. 4A and B). In addition, the decrease of CIP2A protein expression was accompanied by a concomitant reduction in
p-AKT levels and corresponding change of apoptosis-related indicators (Fig. 4B). To determine the causal relationship between AKT phosphorylation and CIP2A expression, we tested the level of p-AKT in the sh-Control and sh-CIP2A bladder cancer cells. The western blotting results revealed that there was no significant difference between the two 
A
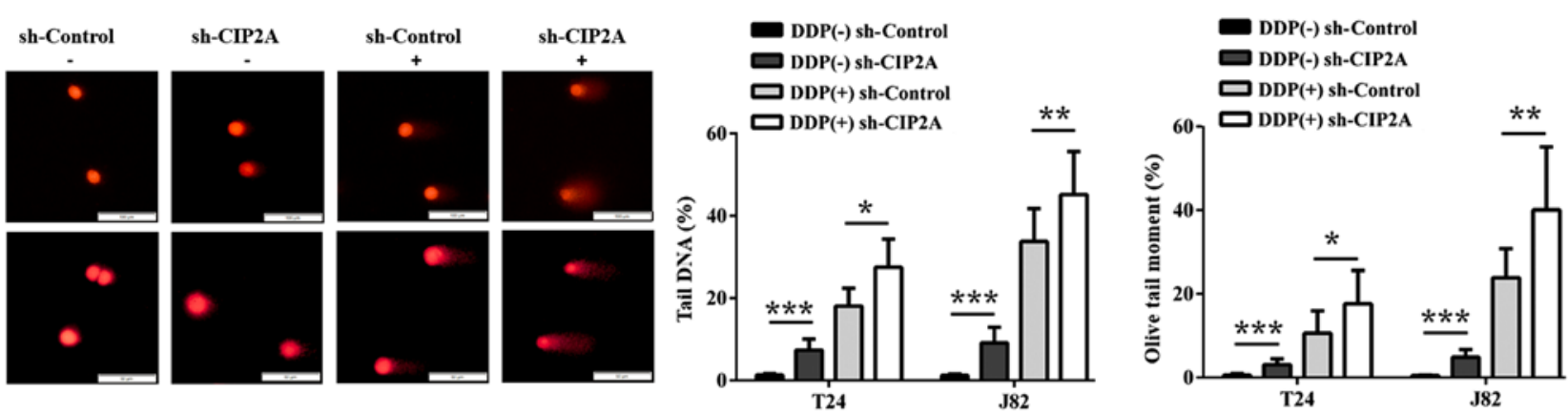

B
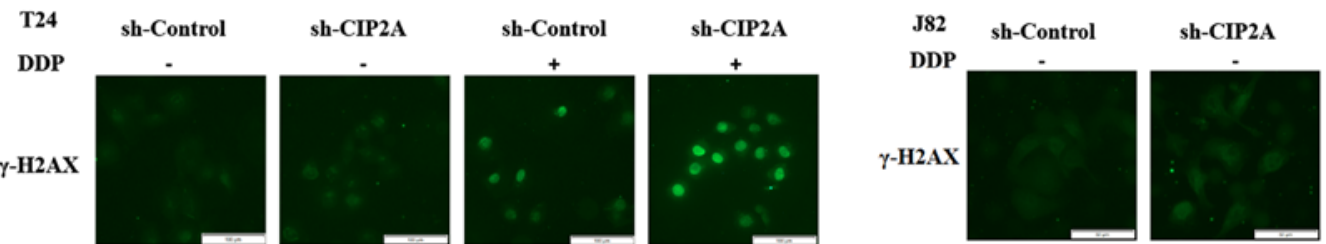

sh-Control
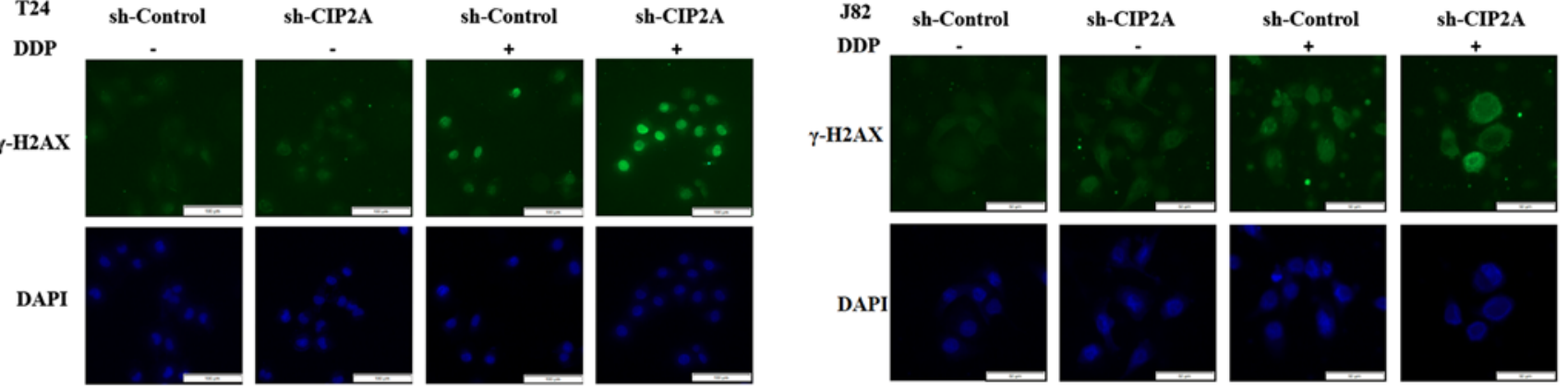

C

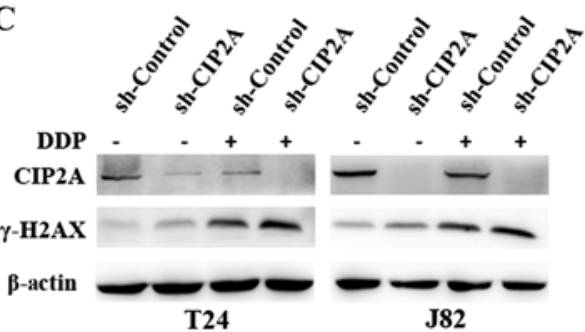

Figure 3. Knockdown of CIP2A in bladder cancer cells enhances DDP-induced DNA damage. (A) Following 0 or $20 \mu \mathrm{g} / \mathrm{ml}$ DDP treatment for $24 \mathrm{~h}$ in sh-Control and sh-CIP2A T24 and J82 cells, a comet assay was performed to assess DNA damage. Scale bar, $50 \mu \mathrm{m}$. (B) Immunofluorescence was performed to demonstrate the formation of $\gamma-\mathrm{H} 2 \mathrm{AX}$ foci. Scale bar, $100 \mu \mathrm{m}$. (C) Western blotting of CIP2A and $\gamma-\mathrm{H} 2 \mathrm{AX}$ proteins was conducted. Every experiment was conducted at least 3 times. ${ }^{*} \mathrm{P}<0.05,{ }^{* *} \mathrm{P}<0.01,{ }^{* * *} \mathrm{P}<0.001$. DDP, cisplatin; sh, short hairpin; CIP2A, cancerous inhibitor of protein phosphatase $2 \mathrm{~A}$.

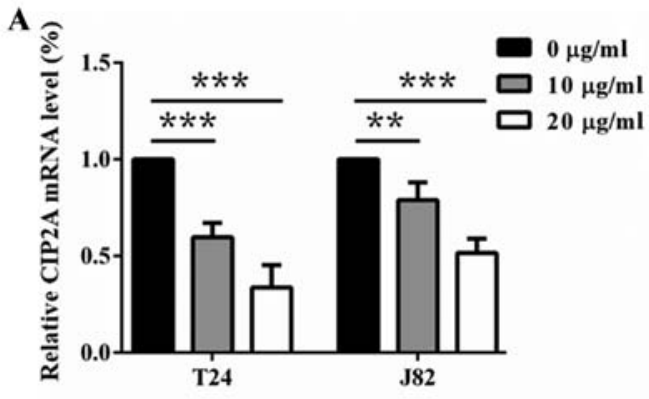

C

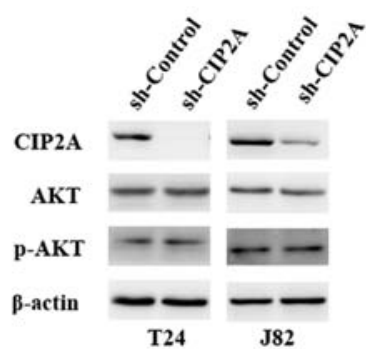

B

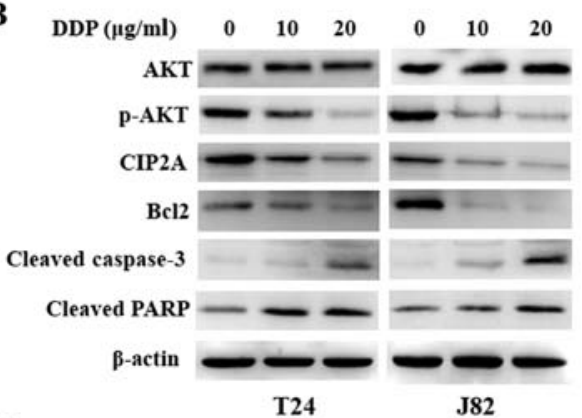

D

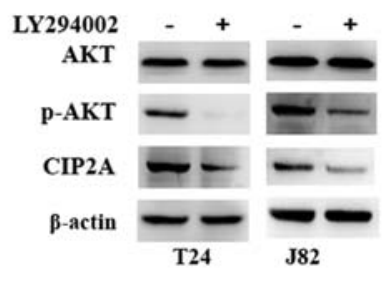

Figure 4. DDP attenuates the expression of CIP2A via the AKT pathway in bladder cancer cells. Upon DDP treatment at different concentrations $(0,10,20 \mu \mathrm{g} / \mathrm{ml})$ in T24 and J82 cells, CIP2A mRNA levels were determined by (A) RT-qPCR, and (B) the protein levels of AKT, p-AKT, CIP2A, Bcl2, cleaved caspase-3, and cleaved PARP were determined by western blotting. (C) The protein levels of AKT, p-AKT and CIP2A in sh-Control and sh-CIP2A T24 and J82 cells were detected by western blotting. (D) Following $20 \mu \mathrm{mol} / \mathrm{l} \mathrm{LY} 294002$ treatment for $24 \mathrm{~h}$, western blotting was used to test the protein levels of AKT, p-AKT and CIP2A in T24 and J82 cells. Every experiment was conducted at least 3 times. ${ }^{* * *} \mathrm{P}<0.01,{ }^{* * * *} \mathrm{P}<0.001$. DDP, cisplatin; sh, short hairpin; CIP2A, cancerous inhibitor of protein phosphatase $2 \mathrm{~A}$. 
A

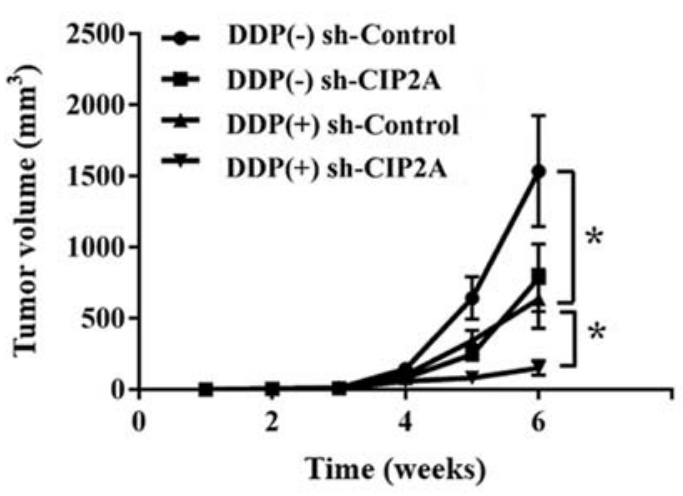

C

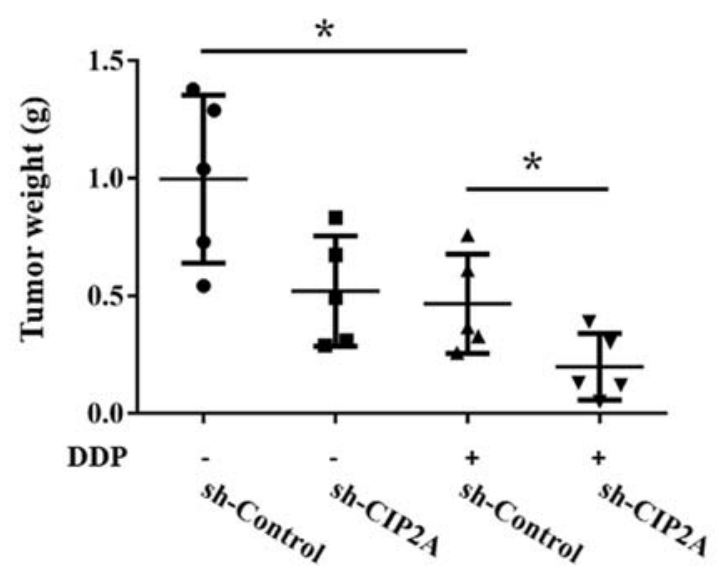

B

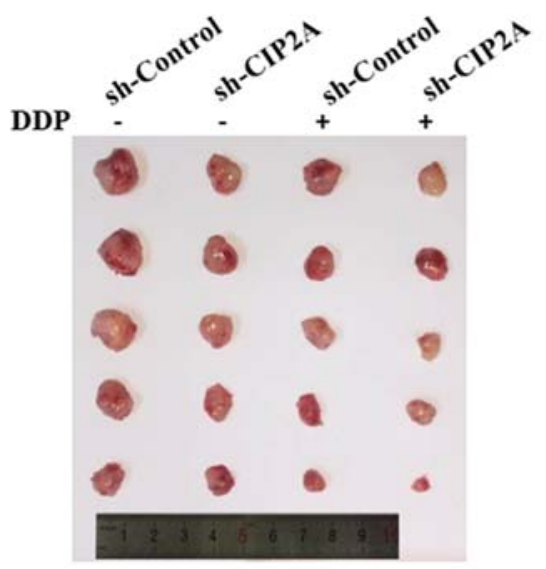

D

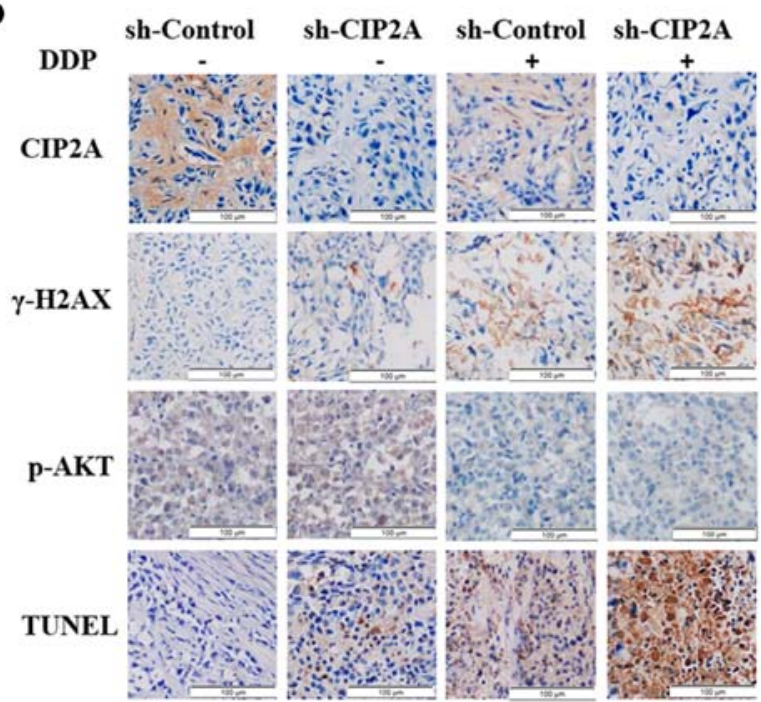

Figure 5. Inhibiting CIP2A expression enhances DDP sensitivity in nude mouse xenografts. (A) Tumor growth curve of sh-CIP2A or sh-Control T24 cell bladder cancer subcutaneous xenograft tumors was built following DDP treatment. (B) Photographs of dissected xenograft tumors from nude mice after they were sacrificed. (C) The weight of dissected xenograft tumors in each group was assayed. (D) IHC staining was performed to detect the expression levels of CIP2A, p-AKT and $\gamma$-H2AX, and TUNEL staining was conducted to test the degree of apoptosis in harvested tumor tissues. Representative photomicrographs of 200-fold high power fields in each group are presented. Scale bar, $100 \mu \mathrm{m} .{ }^{*} \mathrm{P}<0.05$. DDP, cisplatin; sh, short hairpin; CIP2A, cancerous inhibitor of protein phosphatase $2 \mathrm{~A}$; IHC, immunohistochemistry.

cell lines (Fig. 4C). However, the expression of CIP2A was downregulated when treated with LY294002, an inhibitor to phosphorylation of AKT (Fig. 4D). These results provided evidence that CIP2A is a downstream effector in the AKT signaling pathway, through which DDP inhibits CIP2A expression in bladder cancer cells.

Inhibition of CIP2A expression enhances DDP sensitivity in nude mouse xenografts. A nude mouse xenograft model was established using sh-Control and sh-CIP2A T24 cells to verify our previous conclusions in vivo. After intraperitoneal administration of DDP for 3 weeks, tumors in the sh-CIP2A group grew at a slower rate (Fig. 5A and B), accompanied by significant reductions in weight (Fig. 5C). Further analysis yielded the additional information that the inhibitory rates of the sh-CIP2A group and sh-Control group were 79.7 and 54.9\% respectively, revealing the increased DDP sensitivity caused by CIP2A knockdown. Compared with the DDP(+) sh-Control group, the TUNEL assays revealed that the percentage of apoptotic cells was markedly higher in the DDP(+) sh-CIP2A group. In addition, the IHC assay illustrated a stronger positive stain of $\gamma$-H2AX (Fig. 5D). According to the IHC staining results, the positive rates of both p-AKT and CIP2A in tumors undergoing a DDP therapeutic regimen were markedly decreased (Fig. 5D). These results supported the hypothesis that inhibition of CIP2A expression enhanced DDP sensitivity in vivo.

\section{Discussion}

DDP is the backbone of several mainstream chemotherapeutic regimens for advanced bladder cancer, in particular in patients with distant metastasis (1). Two large, randomized trials clearly supported the idea that DDP provides 5-year cancer-specific survival benefits compared with surgery alone in patients with MIBC $(3,4)$. However, relatively poor response and chemotherapy resistance frequently lead to treatment failure (21). Thus, it is urgent to discover novel approaches to increasing sensitivity to DDP, which remains poorly understood. In the present study, we focused our research on the involvement of 
CIP2A in DDP-induced DNA damage and cell apoptosis to enhance the chemosensitivity of DDP.

CIP2A is a human oncoprotein, which has been confirmed to be overexpressed in bladder cancer (22). Huang et al (23) confirmed that the levels of specific CIP2A protein increase with increasing tumor grade and stage of bladder cancer. Furthermore, several recent studies also have provided evidence of the potent role of CIP2A in bladder cancer cell proliferation and epithelial mesenchymal transition $(16,24)$. Thus, it is plausible to infer the potential role that CIP2A serves as a prognostic indicator and therapeutic target for bladder cancer.

The intrastrand cross-links of purine bases and DDP are responsible for the process of DSBs, blocking cell division and resulting in apoptotic cell death, which contributes to DDP cytotoxicity (11). Hence, DNA damage-induced apoptosis is a promising target for increasing the sensitivity of DDP. Several molecular mechanisms leading to apoptosis have been found to be implicated in DDP treatment of human cancers, such as the MAPK (25), JNK (26) and AKT pathway (27). In a screen of diagnostic chronic myeloid leukemia samples, samples with low CIP2A levels were characterized by upregulation of pro-apoptotic BCL-2 family members (28). Furthermore, a series of studies confirmed that CIP2A is implicated in apoptosis with a potent chemo-sensitizing potential $(29,30)$. The view of previous researchers is further validated by our results that CIP2A knockdown enhanced sensitivity to DDP by promoting DDP-induced bladder cancer cell apoptosis.

In molecular terms, aggravating DNA damage is an important target to improve the efficacy of DDP-based neoadjuvant therapy. The most revealing evidence supports the development of hypersensitivity to DDP by accumulation of DNA fragments in various malignancies $(31,32)$. Basu et al $(35)$ confirmed that checkpoint kinase Chk1 inhibition explains the cell-killing activity of DNA-damaging agents (33-35). Increased Chk1 activity promotes CIP2A transcription, and CIP2A downregulation is essential for maximal inhibition of cancer cell viability in response to Chk1 inhibition (36). We have considered the close association between CIP2A and DNA damage. Our data indicated that CIP2A depletion induced DNA damage and exacerbated DDP-induced formation of $\gamma-\mathrm{H} 2 \mathrm{AX}$ foci, confirming the hypothesis and elucidating the role of CIP2A in the process of chemotherapeutic drug-induced DNA damage. DNA repair is one of the main mechanisms underlying DDP resistance. Extensive progress has been made in the field of DNA-repair related genes as prognostic markers for DDP treatment in bladder cancer (14). In addition, Myant et al (37) demonstrated that CIP2A is indispensable for the efficient recovery and regeneration of intestinal tissue in response to DNA damage by promoting MYC Ser62 phosphorylation, implying the potential ability of CIP2A to resist DNA damage. Thus, the association between CIP2A and DNA repair requires further investigation.

AKT belongs to a family of serine/threonine kinases which impacts on multiple cellular processes, including cell proliferation and survival (38). AKT activation is achieved by regulation of its phosphorylation status, predominantly on two highly conserved residues, Thr308 and Ser473 (39). It is accepted that AKT activation by Ser473 phosphorylation prevents apoptosis following ionizing radiation-induced
DNA damage (40). Our results also revealed the inhibition of AKT Ser473 phosphorylation by DDP, confirming the viewpoint that DDP-induced DNA damage is AKT-dependent once again (41). Furthermore, in the present study, our data revealed that CIP2A downregulation was triggered by AKT inactivation, indicating that CIP2A acted downstream of AKT. However, several studies hold different opinions that CIP2A controls the activity of AKT by promoting its Ser473 phosphorylation $(42,43)$. However, with regard to the controversial issue, Wiegering et al (44) reported that CIP2A depletion did not affect AKT Ser473 phosphorylation in various colon cancer cell lines, which is consistent with our results. Therefore, further studies are needed to clarify the relationship between the CIP2A and AKT pathway.

Acquiring the appropriate biomarkers, which could help clinicians to identify patients who will really benefit from the DDP-based chemotherapy is a major issue. Multiple molecular biomarker candidates have been studied, including regulators of apoptosis, cell survival and cellular mechanisms of drug uptake and transport (12). However, none have shown clinical utility. Based on the evidence of the critical role of CIP2A in sensitizing bladder cancer cells to DDP in the present study, CIP2A may be an innovative molecular biomarker, which can be used to predict a response to DDP, which could lead to optimizing the individualized therapeutic regimen.

In summary, we have provided evidence that DDP triggered the inhibition of CIP2A expression via promoting the AKT inactivation. In addition, CIP2A knockdown increased DDP-induced bladder cancer cell apoptosis by accelerating DNA damage, revealing CIP2A as a promoter of sensitivity to DDP. Further investigation of the AKT/CIP2A pathway should clarify the detailed mechanism and could give new insights leading to a better curative effect of DDP-based therapy in bladder cancer treatment.

\section{Acknowledgements}

Not applicable.

\section{Funding}

The present study was supported by the National Natural Science Foundation of China (no. 81472379 to ZS) and Zhejiang Provincial Natural Science Foundation of China (no. LY16H160016 to SC). The present study was supported by the Shanghai Key Laboratory of Reproductive Medicine, School of Medicine, Shanghai Jiaotong University.

\section{Availability of data and materials}

The datasets used during the present study are available from the corresponding author upon reasonable request.

\section{Ethics approval and consent to participate}

Animal experiments were performed according to the protocol approved by the Institutional Animal Care and Use Committee (IACUC) of Ruijin Hospital Affiliated to the School of Medicine, Shanghai Jiaotong University. 


\section{Authors' contributions}

$\mathrm{ZS}$ and SZ conceived and designed the experiments. FG, XiaoW, SC and TX performed the experiments. XianW, YS and FD coordinated the research and analyzed the data. FG and XiaoW wrote the manuscript. All authors read and approved the manuscript and agree to be accountable for all aspects of the research in ensuring that the accuracy or integrity of any part of the work are appropriately investigated and resolved.

\section{Patient consent for publication}

Not applicable.

\section{Competing interests}

The authors declare that they have no competing interests.

\section{References}

1. Trenta P, Calabro F, Cerbone L and Sternberg CN: Chemotherapy for Muscle-invasive bladder cancer. Curr Treat Options Oncol 17: 6, 2016.

2. Massari F, Santoni M, Ciccarese C, Brunelli M, Conti A, Santini D, Montironi R, Cascinu S and Tortora G: Emerging concepts on drug resistance in bladder cancer: Implications for future strategies. Crit Rev Oncol Hematol 1: 81-90, 2015.

3. Grossman HB, Natale RB, Tangen CM, Speights VO, Vogelzang NJ, Trump DL, deVere White RW, Sarosdy MF, Wood DJ, Raghavan D and Crawford ED: Neoadjuvant chemotherapy plus cystectomy compared with cystectomy alone for locally advanced bladder cancer. N Engl J Med 9: 859-866, 2003.

4. International Collaboration of Trialists; Medical Research Council Advanced Bladder Cancer Working Party (now the National Cancer Research Institute Bladder Cancer Clinical Studies Group); European Organisation for Research and Treatment of Cancer Genito-Urinary Tract Cancer Group; Australian Bladder Cancer Study Group; National Cancer Institute of Canada Clinical Trials Group; Finnbladder Norwegian Bladder Cancer Study Group; Club Urologico Espanol de Tratamiento Oncologico Group, Griffiths G, Hall R, et al: International phase III trial assessing neoadjuvant cisplatin, methotrexate, and vinblastine chemotherapy for muscle-invasive bladder cancer: Long-term results of the BA06 30894 trial. J Clin Oncol 16: 2171-2177, 2011.

5. Advanced Bladder Cancer Meta-analysis Collaboration. Neoadjuvant chemotherapy in invasive bladder cancer: A systematic review and meta-analysis. Lancet 361: 1927-1934, 2003.

6. Yafi FA, North S and Kassouf W: First- and second-line therapy for metastatic urothelial carcinoma of the bladder. Curr Oncol 1: e25-e34, 2011.

7. von der Maase H, Sengelov L, Roberts JT, Ricci S, Dogliotti L, Oliver T, Moore MJ, Zimmermann A and Arning M: Long-term survival results of a randomized trial comparing gemcitabine plus cisplatin, with methotrexate, vinblastine, doxorubicin, plus cisplatin in patients with bladder cancer. J Clin Oncol 23: 4602-4608, 2005.

8. Dasari S and Tchounwou PB: Cisplatin in cancer therapy: Molecular mechanisms of action. Eur J Pharmacol 740: 364-378, 2014.

9. Cummings BS, Lasker JM and Lash LH: Expression of glutathione-dependent enzymes and cytochrome P450s in freshly isolated and primary cultures of proximal tubular cells from human kidney. J Pharmacol Exp Ther 293: 677-685, 2000.

10. Galluzzi L, Vitale I, Michels J, Brenner C, Szabadkai G, Harel-Bellan A, Castedo M and Kroemer G: Systems biology of cisplatin resistance: Past, present and future. Cell Death Dis 5: e1257, 2014.

11. Galluzzi L, Senovilla L, Vitale I, Michels J, Martins I, Kepp O, Castedo M and Kroemer G: Molecular mechanisms of cisplatin resistance. Oncogene 31: 1869-1883, 2012.
12. Buttigliero C, Tucci M, Vignani F, Scagliotti GV and Di Maio M: Molecular biomarkers to predict response to neoadjuvant chemotherapy for bladder cancer. Cancer Treat Rev 54: 1-9, 2017.

13. Quinn JE, Kennedy RD, Mullan PB, Gilmore PM, Carty M, Johnston PG and Harkin DP: BRCA1 functions as a differential modulator of chemotherapy-induced apoptosis. Cancer Res 63: 6221-6228, 2003.

14. Hoffmann AC, Wild P, Leicht C, Bertz S, Danenberg KD, Danenberg PV, Stöhr R, Stöckle M, Lehmann J, Schuler M and Hartmann A: MDR1 and ERCC1 expression predict outcome of patients with locally advanced bladder cancer receiving adjuvant chemotherapy. Neoplasia 8: 628-636, 2010.

15. De P, Carlson J, Leyland-Jones B and Dey N: Oncogenic nexus of cancerous inhibitor of protein phosphatase 2A (CIP2A): An oncoprotein with many hands. Oncotarget 5: 4581-4602, 2014.

16. Gao F, Xu T, Wang X, Zhong S, Chen S, Zhang M, Zhang X, Shen Y, Wang X, Xu C and Shen Z: CIP2A mediates fibronectin-induced bladder cancer cell proliferation by stabilizing $\beta$-catenin. J Exp Clin Cancer Res 36: 70, 2017.

17. Wang CY, Chao TT, Chang FY, Chen YL, Tsai YT, Lin HI, Huang YC, Shiau CW, Yu CJ and Chen KF: CIP2A mediates erlotinib-induced apoptosis in non-small cell lung cancer cells without EGFR mutation. Lung Cancer 85: 152-160, 2014.

18. Xu P, Yao J, He J, Zhao L, Wang X, Li Z and Qian J: CIP2A down regulation enhances the sensitivity of pancreatic cancer cells to gemcitabine. Oncotarget 7: 14831-14840, 2016.

19. Livak KJ and Schmittgen TD: Analysis of relative gene expression data using real-time quantitative PCR and the 2(-Delta Delta C(T)) method. Methods 4: 402-408, 2001.

20. Rajeswaran A, Trojan A, Burnand B and Giannelli M: Efficacy and side effects of cisplatin- and carboplatin-based doublet chemotherapeutic regimens versus non-platinum-based doublet chemotherapeutic regimens as first line treatment of metastatic non-small cell lung carcinoma: A systematic review of randomized controlled trials. Lung Cancer 59: 1-11, 2008.

21. David KA, Milowsky MI, Ritchey J, Carroll PR and Nanus DM: Low incidence of perioperative chemotherapy for stage III bladder cancer 1998 to 2003: A report from the National Cancer Data Base. J Urol 178: 451-454, 2007.

22. Xue Y, Wu G, Wang X, Zou X, Zhang G, Xiao R, Yuan Y, Long D, Yang J, Wu Y, et al: CIP2A is a predictor of survival and a novel therapeutic target in bladder urothelial cell carcinoma. Med Oncol 30: 406, 2013.

23. Huang LP, Savoly D, Sidi AA, Adelson ME, Mordechai E and Trama JP: CIP2A protein expression in high-grade, high-stage bladder cancer. Cancer Med 1: 76-81, 2012.

24. Pang X, Fu X, Chen S, Zhu X, Qi H, Li Y, Li F and Tan W: Overexpression of CIP2A promotes bladder cancer progression by regulating EMT. Clin Transl Oncol 18: 289-295, 2016.

25. Basu A and Tu H: Activation of ERK during DNA damage-induced apoptosis involves protein kinase Cdelta. Biochem Biophys Res Commun 334: 1068-1073, 2005.

26. Jones EV, Dickman MJ and Whitmarsh AJ: Regulation of p73-mediated apoptosis by c-Jun N-terminal kinase. Biochem J 405: 617-623, 2007.

27. Hayakawa J, Mittal S, Wang Y, Korkmaz KS, Adamson E, English $\mathrm{C}$, Ohmichi $\mathrm{M}$, McClelland $\mathrm{M}$ and Mercola D: Identification of promoters bound by c-Jun/ATF2 during rapid large-scale gene activation following genotoxic stress. Mol Cell 16: 521-535, 2004.

28. Lucas CM, Milani M, Butterworth M, Carmell N, Scott LJ, Clark RE, Cohen GM and Varadarajan S: High CIP2A levels correlate with an antiapoptotic phenotype that can be overcome by targeting BCL-XL in chronic myeloid leukemia. Leukemia 30: 1273-1281, 2016.

29. Janghorban M, Farrell AS, Allen-Petersen BL, Pelz C, Daniel CJ, Oddo J, Langer EM, Christensen DJ and Sears RC: Targeting c-MYC by antagonizing PP2A inhibitors in breast cancer. Proc Natl Acad Sci USA 111: 9157-9162, 2014.

30. Chao TT, Wang CY, Chen YL, Lai CC, Chang FY, Tsai YT, Chao CH, Shiau CW, Huang YC, Yu CJ and Chen KF: Afatinib induces apoptosis in NSCLC without EGFR mutation through Elk-1-mediated suppression of CIP2A. Oncotarget 6: 2164-2179, 2015.

31. McLaughlin M, Barker HE, Khan AA, Pedersen M, Dillon M, Mansfield DC, Patel R, Kyula JN, Bhide SA, Newbold KL, et al: HSP90 inhibition sensitizes head and neck cancer to platin-based chemoradiotherapy by modulation of the DNA damage response resulting in chromosomal fragmentation. BMC Cancer 17: 86, 2017. 
32. Kritsch D, Hoffmann F, Steinbach D, Jansen L, Mary Photini S, Gajda M, Mosig AS, Sonnemann J, Peters S, Melnikova M, et al: Tribbles 2 mediates cisplatin sensitivity and DNA damage response in epithelial ovarian cancer. Int J Cancer 141: 1600-1614, 2017.

33. Smith J, Tho LM, Xu N and Gillespie DA: The ATM-Chk2 and ATR-Chk1 pathways in DNA damage signaling and cancer. Adv Cancer Res 108: 73-112, 2010.

34. Ma CX, Janetka JW and Piwnica-Worms H: Death by releasing the breaks: CHK1 inhibitors as cancer therapeutics. Trends Mol Med 17: 88-96, 2011.

35. Basu B, Yap TA, Molife LR and de Bono JS: Targeting the DNA damage response in oncology: Past, present and future perspectives. Curr Opin Oncol 24: 316-324, 2012.

36. Khanna A, Kauko O, Böckelman C, Laine A, Schreck I, Partanen JI, Szwajda A, Bormann S, Bilgen T, Helenius M, et al: Chk1 targeting reactivates PP2A tumor suppressor activity in cancer cells. Cancer Res 73: 6757-6769, 2013.

37. Myant K, Qiao X, Halonen T, Come C, Laine A, Janghorban M, Partanen JI, Cassidy J, Ogg EL, Cammareri P, et al: Serine 62-phosphorylated MYC associates with nuclear lamins and its regulation by CIP2A is essential for regenerative proliferation. Cell Rep 12. 1019-1031, 2015.

38. Manning BD and Cantley LC: AKT/PKB signaling: Navigating downstream. Cell 129: 1261-1274, 2007.

39. Liao Y and Hung MC: Physiological regulation of Akt activity and stability. Am J Transl Res 2: 19-42, 2010.
40. Bozulic L, Surucu B, Hynx D and Hemmings BA: PKBalpha/Akt1 acts downstream of DNA-PK in the DNA double-strand break response and promotes survival. Mol Cell 30: 203-213, 2008.

41. Hayakawa J, Ohmichi M, Kurachi H, Kanda Y, Hisamoto K, Nishio Y, Adachi K, Tasaka K, Kanzaki T and Murata Y: Inhibition of BAD phosphorylation either at serine 112 via extracellular signal-regulated protein kinase cascade or at serine 136 via Akt cascade sensitizes human ovarian cancer cells to cisplatin. Cancer Res 60: 5988-5994, 2000

42. Tseng LM, Liu CY, Chang KC, Chu PY, Shiau CW and Chen KF: CIP2A is a target of bortezomib in human triple negative breast cancer cells. Breast Cancer Res 14: R68, 2012.

43. Chen KF, Liu CY, Lin YC, Yu HC, Liu TH, Hou DR, Chen PJ and Cheng AL: CIP2A mediates effects of bortezomib on phospho-Akt and apoptosis in hepatocellular carcinoma cells. Oncogene 29: 6257-6266, 2010.

44. Wiegering A, Pfann C, Uthe FW, Otto C, Rycak L, Mäder U, Gasser M, Waaga-Gasser AM, Eilers M and Germer CT: CIP2A influences survival in colon cancer and is critical for maintaining Myc expression. PLoS One 10: e75292, 2013.

(i) () This work is licensed under a Creative Commons Attribution-NonCommercial-NoDerivatives 4.0 International (CC BY-NC-ND 4.0) License. 